\title{
La Ventana Infinita. Método de educación no formal, resiliencia y participación comunitaria
}

\author{
The Infinite Window. Non-formal education, \\ resilience and community participation methods
}

\author{
Teresa Lobo ${ }^{1}$ y Teresa Yurén ${ }^{2}$ \\ Recibido 11/08/2020; Aceptado: 12/04/2021 \\ http://dx.doi.org/10.30972/dpd.10154828
}

\section{Resumen}

Presentamos La Ventana Infinita, un método de educación no formal dirigido a población en situación de desventaja social que, mediante el arte, estimula la resiliencia, el empoderamiento y la participación individual y comunitaria. Describimos cómo se gestó el método, los elementos conceptuales que lo estructuran y sus principales elementos. La Ventana Infinita es también el núcleo que dinamiza un modelo de intervención para población rural dispersa, denominado la Red Flexible, que también se expone aquí. Este método permite corroborar el supuesto freiriano de que la educación es una praxis cuando se hace efectiva la dialéctica teoría y práctica. Identificamos que el desarrollo de procesos artísticos en proyectos de participación comunitaria contribuye a generar un sentido de agencia y al empoderamiento de individuos y comunidades. Concluimos que un proceso educativo realizado con mirada holística y enriquecido por el análisis permite construir alternativas para atender las necesidades comunitarias de manera sostenible. Que el proceso sensible de La Ventana Infinita contribuye a que el participante reconozca y exprese sus necesidades, particularmente las de tipo radical, además de promover activamente la empatía, que es el principio de la articulación de la Red Flexible.

Palabras clave: educación mediante el arte; educación no formal; participación comunitaria; proceso sensible.

\footnotetext{
${ }^{1}$ Teresa Lobo, pintora y directora de La Ventana. Correo electrónico: trsalobo@gmail.com

${ }^{2}$ Teresa Yurén, Dra. en Filosofía, Universidad Autónoma del Estado de Morelos. Correo electrónico: yurent@uaem.mx
} 


\begin{abstract}
We present La Ventana Infinita, a method of non-formal education aimed at socially disadvantaged populations that, through art, stimulates resilience, empowerment, and individual and community participation. We describe how the method was developed, the conceptual elements that structure it, and its main elements. The Infinite Window is also the nucleus that energizes an intervention model for dispersed rural populations, called the La Red Flexible (The Flexible Network), which is also presented here. This method allows us to corroborate the Freirian assumption that education is a praxis when the dialectic of theory and practice is made effective. We identified that the development of artistic processes in community participation projects contributes to the generation of a sense of agency and the empowerment of individuals and communities. We conclude that an educational process carried out with a holistic view and enriched by analysis, allows the construction of alternatives to meet community needs in a sustainable manner. That the sensitive process of La Ventana Infinita contributes to the participant's recognition and expression of their needs, particularly radical needs, in addition to actively promoting empathy, which is the principle of the articulation of La Red Flexible.
\end{abstract}

Keywords: education through art, non-formal education, community participation, sensitive process.

\title{
Introducción
}

Lo que aquí se describe es un largo proceso de sistematización de prácticas de educación no formal, cuyo objetivo fue determinar los principales componentes de un método que, mediante el arte, estimula la resiliencia, el empoderamiento y la participación individual y comunitaria. Este método, denominado La Ventana Infinita, es también el núcleo que dinamiza un modelo de intervención para población rural dispersa, que también se expone aquí.

La Ventana Infinita se inscribe en una tradición abierta desde los años sesenta del siglo XX por Paulo Freire (1978a). En la Pedagogía del oprimido (1978b), este autor insiste en la necesaria relación entre acción y reflexión; sin la primera -decía- hay solo palabrería; sin la segunda, hay activismo. Siguiendo la tradición de la filosofía de la praxis, afirmaba que para transformar el mundo hay que problematizarlo, es decir, pensarlo críticamente a partir de un diálogo en el que el educador es al mismo tiempo educando.

En la línea de la pedagogía crítica, Carr (2002) sostiene la conveniencia de pasar de una práctica no reflexiva (téchne) a una práctica vista como praxis históricamente situada, 
culturalmente implantada, con una carga política y regida por criterios éticos. Desde esta perspectiva, teoría y práctica se constituyen mutuamente y están dialécticamente relacionados.

Vista La Ventana Infinita como un método en el que la teoría busca inscribirse en una práctica transformadora siempre contextuada, no puede considerarse como algo cerrado y acabado pues, como la realidad en la que se aplica, está siempre en proceso y sometido a la crítica y a la mejora, en diálogo permanente con las y los actores del proceso educativo. En congruencia con esto, este método conlleva el pluralismo epistémico (Olivé, cito en JiménezNavarro y Sánchez-Antonio, 2020), que conduce a reconocer y valorar ethos y racionalidades negadas o excluidas por la racionalidad hegemónica. En consecuencia, genera prácticas comunalizantes (Briseño-Roa, 2020), que se inscriben en las formas de vida comunitaria.

Al proponer este método, compartimos con Chacón-Ortiz (2015) el supuesto de que la educación no formal contribuye a la equidad y la justicia social en situaciones de vulnerabilidad, pero creemos que, más que un mero recurso para intervenciones sociales, puede ser un factor de empoderamiento, resiliencia y desarrollo de los individuos y comunidades, si deriva de una lectura ajustada de la realidad (Úcar, 2018), a partir de la cual se favorece al desarrollo de capacidades que permiten a las personas construir su manera de ser, estar y actuar en y con el mundo. Como dice Soler Maso et al. (2017), si se trata de favorecer la autonomía e independencia de las personas, es menester determinar los espacios, momentos y procesos que en cada caso resultan más adecuados para el logro de los objetivos. Por ello, el método que aquí se expone está lejos de ser una especie de receta aplicable de manera homogénea a todos los contextos. Más bien, es un conjunto de principios, postulados y lineamientos que permiten generar intervenciones originales en cada caso.

La exposición se hace en tres apartados. En el primero, se describe cómo se gestó el método y se presentan los elementos conceptuales que lo estructuran. El segundo se dedica a la descripción del método y sus componentes principales, y en el tercero se expone el modelo de intervención vertebrado por el método que aquí exponemos y basado en una experiencia de diez años con comunidades wixaritari. Se cierra el artículo con algunas breves conclusiones.

\section{Génesis del método y referentes conceptuales}

La Ventana Infinita es un método de trabajo mediante el arte, de carácter integrador, sensible y lúdico, diseñado para desarrollar procesos de educación no formal, resiliencia y participación comunitaria, con población en situación de desventaja social. Su objetivo es 
lograr una educación integral que conduzca al participante al reconocimiento de sí mismo en relación con su entorno social y natural, así como a desarrollar capacidades para transformar su situación de vida. Opera mediante el arte, considerando que este es un generador de agencia para la transformación social, que ayuda a empoderar a individuos y comunidades.

Surgió a partir de proyectos realizados en entornos tan diversos como salas de hospital, plazas públicas de la ciudad de México y comunidades indígenas de difícil acceso. Gracias a esta variedad de experiencias, resultó un método flexible, que responde a las necesidades de población en situación de vulnerabilidad y marginación. Es adecuado al trabajo social comunitario, ya que contribuye a superar barreras culturales e idiomáticas y promueve una articulación basada en la empatía y la solidaridad, entre los diferentes actores de la intervención social. Su carácter integral y lúdico permite trabajar en sesiones intensivas que abarcan simultáneamente diversos objetivos, por lo que un solo taller, aun cuando no alcance los logros de un programa de largo plazo, puede tener un impacto múltiple y significativo. Esto es una ventaja para intervenciones sociales en comunidades con escasa oferta educativa y de difícil acceso, donde es inviable hacer visitas frecuentes o estancias prolongadas.

La Ventana Infinita fue diseñada entre 2007 y 2010, y corregida y aumentada en 2015 y $2020^{3}$.

\section{Antecedentes}

Sus antecedentes se encuentran en el trabajo para el desarrollo de resiliencia emocional de infantes hospitalizados y en los talleres de atención y creatividad para niñas y niños de Proyecto ConcentrArte A.C. Sus fundadores, la psicóloga educativa Liliana Riva Palacio y el artista multidisciplinario José Agüero propusieron una parte germinal de los procesos y conceptos de La Ventana Infinita:

Nuestra concepción pedagógica se centra en una imagen caleidoscópica de la educación: trabajar a partir de la estimulación de capacidades personales diferentes, con diversos soportes didácticos (música, estímulo visual, narración oral), haciendo de la experiencia educativa un espacio de transformación situacional de la persona. A partir de los andamiajes didácticos, los niños producen en cada sesión diferentes manifestaciones artísticas (2005).

\footnotetext{
${ }^{3}$ La Ventana Infinita fue diseñada dentro de la asociación mexicana Proyecto ConcentrArte, dedicada al desarrollo de la infancia. En 2019, Teresa Lobo, autora principal de la propuesta, fundó La Ventana, organización dedicada a mejorar la situación de vida de población vulnerable, mediante la educación, la resiliencia y el empoderamiento de individuos y comunidades.
} 
En 2007, la artista plástica Teresa Lobo emprendió el trabajo de investigación que llevó a sistematizar el método con miras a consolidarlo. Como discípula del pintor Gilberto Aceves Navarro, su abordaje de la práctica y la enseñanza del arte se centra en la búsqueda de la expresión sensible, mediante la experimentación libre, la autoexploración, la experiencia sensorial y emocional y el ejercicio del hemisferio derecho del cerebro.

\section{El enfoque integrador y sensible}

El proceso educativo que promueve La Ventana Infinita es integrador, porque propicia que el participante ejercite sus múltiples inteligencias; es sensible, porque favorece un proceso creativo-artístico vinculado a experiencias sensoriales y emocionales. El método se alimenta de elementos teóricos que se mencionan a continuación.

Howard Gardner, en su Teoría de las inteligencias múltiples (1993), distingue ocho inteligencias diferentes e independientes que pueden interactuar y potenciarse entre sí: lógica-matemática, lingüística, visual-espacial, musical, corporal-kinestésica, emocional interpersonal, emocional intrapersonal y naturalista. Guilford (1958) afirma que la creatividad (a la que llama pensamiento divergente) es uno de los componentes de la inteligencia, que se expresa de tres formas: fluidez, flexibilidad y originalidad. Sin negar el factor genético, Guilford y Gardner coinciden en considerar a la inteligencia como una capacidad que puede desarrollarse. Roger W. Sperry (1968) distinguió las funciones de los hemisferios del cerebro, describiendo al izquierdo como racional y al derecho como emocional. Goleman (1995) concluyó que las emociones forman una parte tan integral del pensamiento como la razón y concibió una inteligencia emocional, que conlleva la autoconciencia emocional, la autorregulación emocional, la motivación, la empatía y las habilidades sociales. Al respecto, De Luca (2004) afirma que las personas aprendemos de maneras diferentes, de acuerdo a nuestras inteligencias: una persona con inteligencia corporal-kinestésica aprende moviéndose, mientras otra con inteligencia visual-espacial aprende observando y creando imágenes.

Los sistemas educativos tradicionales basan el aprendizaje en las habilidades lógicomatemáticas y lingüísticas, poniendo en desventaja a personas que no han tenido oportunidad de desarrollarlas, ya sea por rezago educativo, déficit de desarrollo o discapacidad. La Ventana Infinita ofrece al educando la oportunidad de aprender a partir de sus inteligencias, ya sean manuales, visuales, kinestésicas, emocionales, etc., buscando compensar con un sentido de justicia (Elster, 1994) su posición de desventaja. Esto ayuda a superar la barrera del lenguaje, cuando el educando y el educador tienen diferentes lenguas 
maternas. Por esto, La Ventana Infinita es útil para que, por ejemplo, niños(as) indígenas en extrema pobreza y sin habilidades lectoras lleguen a construir nociones como sostenibilidad, ecosistema o derechos humanos.

El proceso sensible juega un papel importante en el aprendizaje. La sensibilidad humana está conformada por la percepción sensorial, las sensaciones físicas, las emociones -procesos físicos y mentales, neurofisiológicos y bioquímicos, breves, de aparición abrupta y con manifestaciones físicas (Marina, cito en Fernández Poncela, 2011)- y los sentimientos que son: emociones culturalmente codificadas, personalmente nombradas y que duran en el tiempo (Fernández Poncela, 2011). El conocimiento se construye en un proceso que va de lo externo a lo interno; es necesario pasar por el conocimiento sensible para llegar al conocimiento intelectual. Percibimos con los sentidos externos (vista, tacto, oído, gusto y olfato) y luego, mediante los sentidos internos (instinto, sentido común, memoria sensible e imaginación), asociamos esas percepciones con nuestras representaciones y nuestras emociones (Selles, 2006). Mientras más percepciones y emociones se asocien a una representación, el nuevo conocimiento será más completo, permanente y accesible a nuestra memoria.

La Ventana Infinita aborda el arte como el lenguaje de la expresión sensible, coincidiendo con las siguientes posiciones. En la concepción del pintor moderno Vasily Kandinsky (1912), el centro del quehacer artístico es el mundo interior que el artista aspira a manifestar: el sentimiento expuesto en voz alta, más tarde o más temprano, guiará correctamente al artista y del mismo modo al observador. Según este artista, lo verdaderamente importante en el arte es si ha surgido de la necesidad interior o no. En el mismo tenor, para Gilberto Aceves Navarro, quien formara a generaciones de artistas, la práctica del dibujo era un laboratorio para la experimentación del proceso sensible-creativo. Decía a sus estudiantes: "Quiero que sean capaces de actuar basados en una investigación constante. De esta manera, evitamos que nuestra observación se vea entorpecida por lo que creemos que sabemos [...] Déjense llevar por su impulso y que sea su sensibilidad la que los guíe, no su reflexión" (Aceves Navarro, cito en Martínez Fernández, 2003: 68). Además, la experiencia sensorial actúa de manera recíproca al pensamiento. En términos de Rudolf Arnheim (2002): Todo percibir es también pensar, todo razonamiento es también intuición, toda observación es también invención.

Si sentir es pensar, si la construcción del conocimiento está tan intrínsecamente relacionada con nuestros sentidos y nuestras emociones, ¿por qué no enriquecer el proceso educativo con la experiencia sensible? La Ventana Infinita asocia el aprendizaje a una diversidad de percepciones, sensaciones, emociones y sentimientos que lo enriquecen y lo hacen significativo, propiciando así la toma de conciencia. 


\section{Educación mediante el arte para la acción transformadora}

¿A qué nos referimos con toma de conciencia? El objetivo de La Ventana Infinita es que el participante se reconozca a sí mismo, en relación con su entorno social y natural. Reconocerse a sí mismo implica que pueda ubicar y expresar qué siente y qué necesita. Reconocer su relación con su entorno social y natural significa poder mirar su realidad desde una perspectiva holística, que revela interdependencia de factores sociales, ambientales y de salud física y emocional. Esta toma de conciencia o como la llamó Freire, concienciación, "procura dar al hombre la oportunidad de redescubrirse mientras asume reflexivamente el propio proceso en que él se va descubriendo, manifestando y configurando" (Freire, 1978b).

El método ofrece al participante contenidos educativos que contribuyan a la compresión de los problemas en que está inmerso y las repercusiones de estos en su vida, su ambiente y su cultura. Luego, el participante reconstruye estos contenidos en una secuencia de actividades lúdicas, didácticas y artísticas, rica en experiencias sensibles. Este proceso busca que la población en situación de vulnerabilidad encuentre las causas y consecuencias de sus problemas y pueda reconocer, priorizar y expresar sus necesidades. En un proyecto comunitario de largo plazo, estos contenidos han de ser construidos por la propia comunidad, que irá creando su propia narrativa, delimitando y priorizando los problemas a atender. Como propone Freire en el método dialógico, nosotros seremos observadores que registren la lectura que la comunidad hace del mundo para descubrir su universo temático (Freire, 1978b). La Ventana Infinita propone hacer esta observación en los procesos de creación artística colectiva, de modo que ese diálogo se construya no slo con palabras, sino con imágenes, colores, movimientos, gestos, sonidos, etc. De este modo, una obra de teatro, un foto-reportaje, un mapa hecho con ramas y hojas, una canción, etc., revelan a la propia comunidad cuáles son los temas y problemas que le son más significativos.

La toma de conciencia sobre la propia realidad no tendría mayor sentido si no se desarrollan capacidades para transformarla. Para ello, La Ventana Infinita favorece tres disposiciones: el compromiso personal, la resiliencia emocional y la participación comunitaria.

Con Amartya Sen (2010) consideramos que el desarrollo de capacidades es la condición que hace posible que las personas puedan llevar a cabo la vida que eligen, y la agencia es la habilidad para definir y perseguir las propias metas de manera autónoma. La agencia está asociada a lo que Nussbaum (1999) considera las capacidades humanas mínimas necesarias para las condiciones de una vida digna: la vida misma; la salud física; la integridad corporal; los sentidos, la imaginación y el pensamiento; las emociones; la razón práctica; la adscripción 
social o afiliación; otras especies (la relación con la naturaleza); el juego y el control sobre el propio medio. Siguiendo a Sen, Pick et al. (2007) aseguran que empoderamiento y agencia

son procesos que ocurren en el nivel individual. No obstante, el proceso de desarrollar agencia usualmente tiene implicaciones a nivel social. Una vez que la agencia comienza a impactar en la familia, los colegas, las organizaciones y la comunidad, se convierte en empoderamiento. El proceso de desarrollar empoderamiento a menudo sucede en etapas, con la meta final de desarrollo en el nivel comunitario más amplio (Pick et al., 2007: 297).

Con base en estos conceptos, La Ventana Infinita procura el desarrollo de capacidades que dignifiquen la vida de población en situación de vulnerabilidad y recurre a la creación artística como un generador de agencia porque el arte es un proceso de transformación que lleva al creador, como individuo y como colectividad, a tomar conciencia de su capacidad para transformarse a sí mismo y al mundo que lo rodea (Lobo, 2020, inédito).

El método se rige por los siguientes principios: 1. Promover un arte de todos y para todos, considerando que toda persona es capaz de hacer arte, y 2. Poner énfasis en que lo único que se necesita para crear es la voluntad creadora. Hace énfasis en la producción artística con materiales colectados (de re-uso y encontrados en la naturaleza), para mostrar a los participantes que hacer arte no depende del conocimiento de técnicas o del acceso a materiales. Una persona, aun en condición de vulnerabilidad, se empodera cuando logra, por ejemplo, transformar un montón de basura en algo único y maravilloso, o conmover profundamente a otros usando solo su voz y su cuerpo. El arte, además, es la más poderosa herramienta para el desarrollo de la creatividad; la persona creativa expresa ideas novedosas y da respuestas poco comunes a los problemas (Guilford, 1958). La flexibilidad y la originalidad implican romper estereotipos fuertemente afianzados, lo que supone formar personas que puedan cuestionar y cuestionarse, con una opinión propia y capaces de ejercer su pensamiento crítico. Desde la perspectiva de Kandinsky y Aceves Navarro, la expresión sensible libre, profunda y honesta es condición del arte. Lograrla requiere un proceso de autoexploración sensible, que lleva al creador al reconocimiento de sí mismo. No hay arte sin libertad; por ello, hacer arte es liberador.

El autoconocimiento es factor de resiliencia emocional. La pobreza y los ambientes psicológicamente insanos, por ejemplo, donde existen violencia de género y alcoholismo, son condiciones de alto riesgo para la salud física y mental de las personas; no siempre es posible modificar estas condiciones, que mantienen a las personas en situación de vulnerabilidad. Para que el participante supere lo que está fuera de sus manos resolver, La Ventana Infinita propicia el desarrollo de resiliencia emocional. Edith Grotberg (1995) 
observó que la resiliencia depende de la interacción de tres factores: el soporte social (yo tengo), la fuerza interior (yo soy) y las habilidades (yo puedo). María Angélica Kotliarenco et al. (1997) estudió los factores de la resiliencia en personas en pobreza extrema. De acuerdo con su enfoque, el trabajo para la resiliencia, en lugar de centrarse en las carencias o déficits que mantienen a las personas en situación de presión o riesgo, busca aumentar los factores protectores y las condiciones que posibilitan un desarrollo más sano, reforzando su autoestima, sus fuentes de afecto y sus redes de apoyo, favoreciendo la comunicación, la cooperación y el desarrollo de capacidades para el trabajo organizado y la resolución de conflictos. En gran medida, el ethos comunitario -comunalidad, en términos de Fuente (2012) - es la base de la resiliencia social, ya no solo individual, porque brinda los lazos de solidaridad y amistad, que posibilitan la cooperación y la toma de decisiones colectivas. No se trata de liderazgos, sino de un sentimiento profundo de reconocimiento del pueblo con el que se identifican, del orgullo de formar parte de él y de la seguridad de mantener el vínculo con el universo gracias a esa cultura.

La Ventana Infinita propicia activamente la formación de lazos de solidaridad y amistad mediante el trabajo participativo, gracias a la convivencia intensa y gozosa que se da en los procesos lúdicos-sensibles, a la hora de compartir el arte, como creadores o espectadores, la celebración de los logros conjuntos, la participación de los educadores en las fiestas y tradiciones locales. "Es muy importante eso, el acercamiento, el poder platicar... y ya al rato, ya estamos de ¿Cómo le va?, ¿Cómo le fue? Y así nos acercan, con los talleres, con juegos, las pláticas, la música. Nos ayuda a expresarnos más" (Georgina Carrillo, maestra de La Cebolleta, cita en Lobo, 2019a). "He visto que la gente ya aprendió a trabajar en equipo. Se ha visto que trabajando en equipo es más fácil, porque entre todos se apoyan y se divierten, comparten sus ideas, el trabajo, se apoyan unos entre otros" (Luciano Bautista, La Cebolleta, cito en Lobo, 2019a).

Marta Nussbaum (2008: 184) señala que:

En todas las sociedades encontramos una serie de emociones similares [...] Algunos de nuestros apegos intensos, como aquellos que se dirigen hacia nuestros progenitores o cuidadores, o las bases tempranas de la empatía y de la compasión hacia los demás también son fenómenos emocionales omnipresentes.

De acuerdo con Goleman (2002), la empatía es la cualidad de entender y vivir como propios los estados emocionales de otras personas. Eso es lo que ocurre con el arte, entre el creador y el espectador. Si bien, los elementos formales y semánticos del arte están determinados por la cultura, no es el caso de sus elementos expresivos, que no necesitan ser comprendidos, sino sentidos, esto es lo que distingue al arte del resto de las creaciones humanas y lo que lo hace universal y atemporal. Compartir un proceso creativo artístico, cantar, pintar, bailar juntos (tanto en el trabajo como en las ceremonias wixaritari), ha 
permitido establecer un contacto de tipo empático, contribuyendo a salvar barreras culturales e idiomáticas, como sucedió con la comunidad wixárika.

Recuerdo que en nuestra primera ceremonia, Chuy, un anciano de La Cebolleta, me enseñó la forma en que se cosen los listones a los cirios. Ahí descubrí que hay amistades que se forjan con señas y miradas, cuando no se habla la misma lengua. (Lobo, 2019ª: 20).

El método ha resultado muy efectivo para la relación con la comunidad wixárika, dada la importancia que dan a la creación artística. Ellos le otorgan al arte fuertes atributos espirituales, y la música y la creación plástica son parte de sus procesos rituales. El desarrollo de procesos artísticos, en los que despliegan su rico lenguaje visual, les ha resultado muy placentero, haciendo del arte un medio efectivo para que los contenidos del programa educativo les sean significativos.

\section{Construcción del método}

La Ventana Infinita comenzó a construirse con el diseño, la descripción de los procesos de trabajo y la observación de resultados de un curso de arte (Casa Lamm, 2007) y del trabajo para la resiliencia de infantes hospitalizados (Instituto Nacional de Pediatría, 2007). Estos proyectos tenían por objetivo el desarrollo de creatividad y resiliencia de los pequeños que, en talleres e intervenciones teatrales y musicales, vivían la experiencia del arte como espectadores y creadores, de manera alternada y combinada con ejercicios de relajación, concentración, imaginación, percepción sensorial y de reconocimiento y expresión de emociones.

En el último taller, nos sentamos todos en círculo a platicar sobre la experiencia compartida. Me quedo con el comentario de Naomi, de 9 años: "Nunca me había sentido tan libre". Ese mismo día, hicimos una obra en la que participamos los cincuenta y tantos involucrados en el curso, un gran dibujo hecho con flores, piedras y hojas, en el jardín. Cuando Sebastián, de 6 años, lo vio terminado exclamó feliz: "iEstá lleno de amor!". Recuerdo también a Lalo, un pequeño de 4 años, que tras descubrir una mezcla de color, gritó, bañado en pintura: "Soy mago". Estas tres anécdotas, representan lo que esos niños descubrieron sobre el arte, lo que yo amo del arte: el arte es liberador, el arte expresa emociones profundas, el arte es magia. (Lobo, 2020, inédito)

ConcentrArte reunía equipos multidisciplinarios de colaboradores altamente creativos (artistas, sicólogos, científicos, educadores, etc.) que estaban en constante rotación, lo que 
significaba un rico intercambio de saberes, pero dificultaba aprovechar las experiencias anteriores. En 2007, la organización emprendió el proyecto de educación no formal ¡Salvemos Cuatro Ciénegas! Educación ambiental mediante el arte, en escuelas preescolares y primarias aledañas al Área Natural Protegida de Cuatro Ciénegas. Sus contenidos educativos se centraban en explicar las características del ecosistema local, en peligro por la sobreexplotación de su frágil acuífero, buscando concientizar sobre la urgencia de conservar su biodiversidad. Los colaboradores, en su mayoría artistas, eran capaces de guiar a los infantes para establecer un vínculo emocional con su entorno natural y encontraban en los contenidos de educación ambiental temas para las obras de arte. Por ejemplo: los niños se hacían disfraces que representaban a la fauna (tortugas, caracoles y peces) y jugaban a nadar en una poza imaginaria, hasta que esta comenzaba a secarse. Los niños establecían empatía con los habitantes de la poza y se preocupaban por su conservación. Sin embargo, a los artistas se les dificultaba la entrega de los contenidos de ciencia necesarios para que construyeran el problema ambiental. Incluso, se resistían a realizar cualquier cosa que se pareciera a una clase, por su temor a "aburrir" a los niños. A pesar de estas dificultades y resistencias, era importante que el propio equipo de talleristas colaborara en el diseño de los talleres.

\footnotetext{
Quien imparte el taller, nunca debe ser un mero ejecutante. Todo el equipo de colaboradores debe participar de manera activa en su diseño. Mientras más ejerza su creatividad, su labor será más gozosa y tendrán más experiencias creativas que compartir con los niños. Reconocerse como creadores del taller, los hará sentirse libres y capacitados para hacer adaptaciones ante situaciones no previstas, para aprovechar el entorno y las circunstancias en las que se desarrolle el trabajo $y$, un punto muy importante, para inventar nuevas actividades a partir de las propuestas y hallazgos de los niños. (Lobo, 2020, inédito)
}

Se evidenció la necesidad de crear una estructura para el diseño de actividades, suficientemente flexible para aprovechar la creatividad y experiencia de los colaboradores, pero que asegurara el cumplimiento de un conjunto de elementos: la construcción de contenidos educativos, el ejercicio de las inteligencias múltiples, la experiencia sensible, el proceso creativo artístico y la formulación de compromisos. Tras la experimentación, observación, evaluación y ajuste de los procedimientos de trabajo, se delimitó un proceso educativo, llevado a cabo mediante herramientas metodológicas, organizadas en una secuencia de actividades.

\section{La Ventana Infinita: el método y sus componentes}


El método que estamos describiendo se orienta a lograr que los participantes: a) propongan acciones concretas, realizables en su vida cotidiana, que contribuyan a la solución de sus necesidades; b) desarrollen resiliencia emocional para superar problemas cuya solución no está en sus manos, y c) encuentren espacios de expresión y participación en su comunidad. El proceso educativo no formal que se desarrolla incluye los siguientes elementos: 1. Percepción sensorial; 2. Sensación; 3 Emoción; 4. Sentimiento; 5. Conciencia; 6. Compromiso y 7. Acción transformadora (Ver figura 1).

\section{Figura 1. Proceso educativo de La Ventana Infinita}

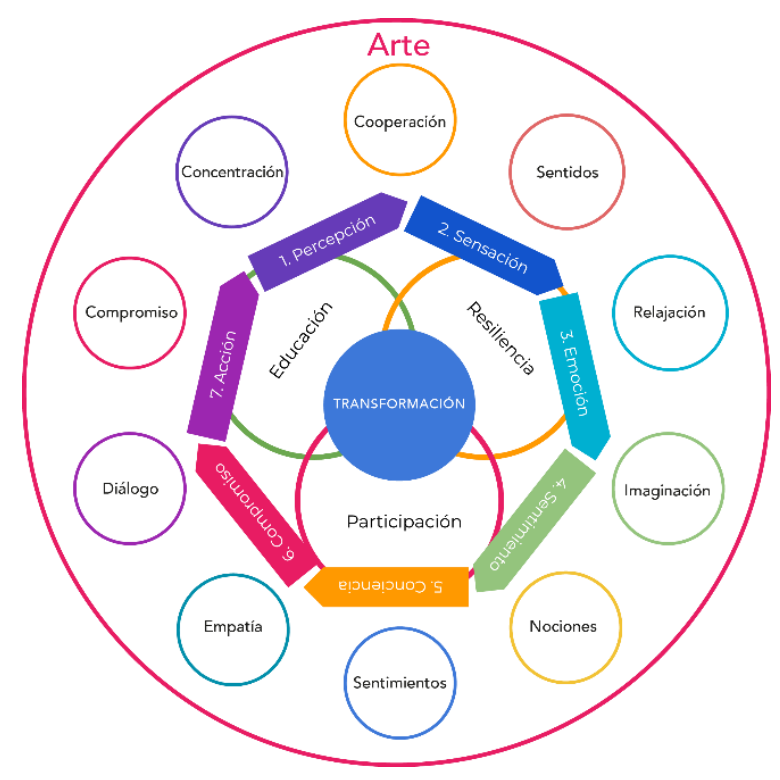

Fuente: elaboración de Teresa Lobo (2020, inédito).

El proceso educativo se desarrolla a lo largo de una secuencia de actividades de cuatro etapas:

1. Vinculación. Implementadores y participantes se presentan y realizan dinámicas lúdicas para entrar en confianza. Se explican los objetivos y lineamientos de la actividad.

2. Presentación de contenidos educativos. Se construyen los contenidos básicos del taller mediante una obra de teatro breve, un audiovisual, un cuento, una plática o un juego didáctico, diseñados específicamente para el programa. 
3. Proceso sensible-artístico. Creación artística, que se mezcla y alterna con actividades para propiciar la percepción sensorial, la sensación, la emoción, el reconocimiento y la expresión de sentimientos.

4. Cierre. Los participantes presentan sus conclusiones sobre cómo atender las necesidades y problemas abordados. Se establecen compromisos personales y acuerdos comunitarios para emprender acciones por el bien propio y el bien común.

Las actividades de esta secuencia se alternan y combinan con la actividad artística, privilegiando los procesos cooperativos, pero dejando siempre espacio a la expresión personal.

El método cuenta con diez herramientas para el diseño de actividades. Incluir las diez herramientas en una secuencia de actividades asegura completar el proceso educativo y trabajar desde las inteligencias múltiples:

1. Juegos de coordinación y concentración

2. Juegos cooperativos

3. Prácticas dialogantes

4. Juegos de representación de nociones

5. Prácticas de relajación

6. Ejercicios de percepción sensorial

7. Juegos de imaginación

8. Ejercicios para promover la empatía

9. Ejercicios de reconocimiento y expresión de emociones

10. Acción simbólica para establecer compromisos

Estas herramientas no son recetas que puedan seguirse sin esfuerzo. El equipo que las implemente, sin importar su formación, deberá poner a prueba sus capacidades creativas y su empatía. Son herramientas abiertas, lo que significa que pueden adaptarse a ellas todo tipo de actividad lúdica y didáctica, mientras cumpla con la descripción de la herramienta (juegos tradicionales, dinámicas propias de la enseñanza artística, prácticas de meditación y actividades que provengan de otros métodos de enseñanza y participación). Una sola actividad puede integrar varias herramientas. Pongamos por ejemplo la actividad El ciclo del agua, que se utiliza en talleres de educación ambiental y que integra el juego de 
representación de nociones y el juego de imaginación:

\begin{abstract}
Hacemos un círculo y les decimos a los niños que vamos a actuar el ciclo del agua. Les pedimos que cierren los ojos y piensen en agua: en el mar, la lluvia, un río, el rocío, etc. ¿cómo suena, cómo se siente, a qué sabe si la probamos? Que se imaginen el agua que corre por sus cuerpos, hasta que ellos mismos se convierten en agua. Les pedimos que abran los ojos e imiten nuestros movimientos. Nos acostamos en el piso y sentimos que flotamos en la superficie de un lago, el sol nos calienta y nos vamos evaporando -nos levantamos lentamente y nos vamos estirando hacia el cielo levantando las manos-, nos convertimos en una nube cada vez más cargada -representamos con todo nuestro cuerpo cómo crece la nube, hinchando los cachetes, subimos tanto que el mundo, desde arriba, se ve pequeño. El aire esta frío, nos hace tiritar. Nos condensamos y comenzamos a caer en forma de lluvia -hacemos gestos con las manos y todo el cuerpo y sonidos de lluvia-, hasta que llegamos a la tierra, regamos las plantas, nos filtramos por el suelo, hasta que un río subterráneo nos lleva de nuevo al lago y el ciclo vuelve a empezar. Hacemos todos los gestos y sonidos que se nos ocurra, utilizando el movimiento de todo el cuerpo. Repetimos el ciclo varias veces, cada vez más rápido, hasta que lo hacemos en sólo unos segundos. (Lobo, 2020, inédito)
\end{abstract}

Esta actividad involucra la expresión corporal y la generación de imágenes mentales, por lo que aprovecha las inteligencias corporal-kinestésica y visual-espacial para construir un contenido de ciencia básica. Propicia que la imaginación, recurriendo a la memoria sensible, provoque una diversidad de sensaciones corporales (calor, frío, vértigo, etc.) para enriquecer la construcción del conocimiento.

Otro ejemplo, usado en educación ambiental, es el Móvil del ecosistema (la descripción citada corresponde a un proyecto de promoción de biodigestores). Se trata de una actividad artística que integra el juego de representación de nociones y la acción simbólica:

1. En el pizarrón, entre todos, hacemos una lista de los elementos del ecosistema que nos rodea, incluyendo plantas, animales y características del terreno, como lagos, ríos, montañas, Ilanos, etc. Además, escribimos los elementos del sistema del biodigestor: milpa o huerto, animales de crianza, caca, biodigestor, humano, biol y biogás; 2 . Cada compañero elige uno o más elementos de la lista para hacer una figura. Podemos hacerlas con todo tipo de material de re-uso y que tengamos a la mano, pero deben ser ligeras y no demasiado grandes, para que puedan colgarse en el móvil. Hacemos una estructura con ramas o palitos y la colgamos; 3. Colgamos las figuras de la estructura, buscando que queden equilibradas; 5 . Jugamos con el móvil. Observamos que se trata de un sistema en el que todo está conectado. Si tocamos una parte, la energía cinética (movimiento) afecta a todo lo demás. Observamos lo que pasa si 
empezamos a quitar elementos (agotar recursos) o a poner cosas que no pertenecen ahí (contaminar); 6. Para terminar, escribimos en un papelito un compromiso con la naturaleza y lo colocamos en el móvil. (Lobo y Enríquez, 2018: 22)

En un programa de talleres para la adopción de ecotecnologías y prácticas sostenibles en comunidades wixaritari, evaluamos si niñas y niños habían construido la noción de sostenibilidad ambiental. Antes de los talleres, les preguntamos: ¿Qué es sostenibilidad? Ninguno conocía la palabra, ni su significado. Solo una niña respondió: "Tiene que ver con sostener algo". Al término de los talleres, ninguno de los niños pudo dar una definición, pero expresaron frases que engloban la idea: "Estamos conectados con los elementos y por eso debemos cuidarlos" o "Son los ciclos naturales". Sin embargo, todos fueron capaces de representar sistemas sostenibles en dibujos esquemáticos que muestran actividades humanas adaptadas a los ciclos naturales (la captación de agua de lluvia con relación al ciclo del agua o un sistema de composteo en la cadena trófica) (Lobo, Cervantes, y Frank, 2016). Algunos niños incluyeron en los esquemas símbolos de la cosmovisión wixárika. La construcción de nociones centrada en procesos no verbales ha permitido superar la diferencia de lenguas entre educandos y educadores, además del hecho de que la mayoría de los pequeños son analfabetos.

A continuación, la descripción de una secuencia de actividades completa, dentro del proyecto Mirar a la guerra para sembrar la paz realizado por ConcentrArte en 2010, en museos de la ciudad de México:

[Previo a la descripción, se realizaron juegos de coordinación y concentración] Los talleres iniciaron con la proyección del audiovisual Mirar a la guerra para sembrar la paz, sobre Goya y su visión crítica de la guerra [presentación de contenidos]. Después, observamos una selección de diez grabados de su serie Los desastres de la guerra, lo que nos dio motivo para reflexionar sobre las causas y consecuencias de la guerra, sobre cómo vivimos la violencia y cómo nos afecta [Ejercicio de reconocimiento de emociones]. En grupo, los niños llegaron a la reflexión de que todos llegamos a ser violentos en algún momento, pero también de que todos podemos ayudar a construir la paz con nuestras acciones cotidianas [práctica dialogante]. Nos dimos un tiempo para compartir nuestros sentimientos y expresar nuestros miedos y preocupaciones por la violencia que se vive en nuestro país [aquí se realizaron ejercicios de relajación]. Después, en un ejercicio en el que teníamos que usar la imaginación, los sentidos y el corazón, jugamos a ponernos en el lugar de otros. Nos miramos a los ojos y luego los cerramos, para tocar y sentir al otro e identificarnos como iguales, percibiendo el calor de sus manos, la forma de su cara, el latido de su corazón [Ejercicio de reconocimiento y expresión de emociones y Ejercicio para promover la empatía]. [Para entrar en contacto con el material de trabajo, se realizó un ejercicio 
de percepción sensorial, tocando, oliendo y sintiendo hojas, ramas y semillas] Llegó la hora de crear en equipo, un nido, un corazón, un árbol, unas alas... Los niños realizaron cuatro instalaciones, intervenciones a cuatro grabados de Los desastres de la guerra de Goya. Recortando, pegando, armando y pintando, los niños cambiaron la situación de violencia de los personajes por un entorno de paz y esperanza. En el proceso, nos reunimos alrededor de nuestra obra para ponerle, con ayuda de la imaginación, todo aquello que nos da paz [Juegos de imaginación]. Los pequeños mencionaron cosas como amor, amistad, tolerancia, juego, salud, mamá, diversión, familia, compartir, gratitud, risa, trabajo en equipo, generosidad, arte, mascotas, naturaleza, abrazos, baile, comprensión. Para concluir, escribieron mensajes de paz y, en un ejercicio voluntario, pusieron la huella de sus manos en la obra colectiva, expresando con esta acción simbólica su compromiso de sembrar y cultivar la paz todos los días. (Lobo, 2011: 13)

En el proceso, los participantes reconocieron las formas en las que cada uno era sujeto de violencia y las actitudes resilientes que contribuyen a superarla. También reconocieron la forma en la que ellos ejercen violencia en su hogar y escuela. El compromiso que cada uno formuló fue evitar ejercer esas formas de violencia en su vida cotidiana y mantener actitudes resilientes para superar la violencia de la que es sujeto.

\section{Etapas de la intervención}

La Ventana Infinita puede aplicarse en un taller único, en un programa corto o en un programa sostenido, que pueden desarrollarse en el marco de un proyecto más amplio, realizado por una red de aliados. Si bien, sus herramientas son sumamente útiles en proyectos breves de educación no formal y divulgación, el método solo alcanzará el logro de sus objetivos en programas de largo plazo que incluyan procesos participativos de evaluación. En estos casos, la intervención se realiza en cuatro etapas que, en los programas sostenidos, son cíclicas. En los proyectos comunitarios han de realizarse actividades participativas en todas las etapas de la intervención, de modo que la comunidad colabore en el diagnóstico, en la generación de contenidos educativos y en la evaluación del proyecto. La primera y la última etapa se traslapan porque las actividades de evaluación funcionan también como un diagnóstico para el siguiente ciclo de la intervención, en un proceso de investigación permanente (Ver figura 2).

\section{Figura 2. Etapas de intervención de La Ventana Infinita}




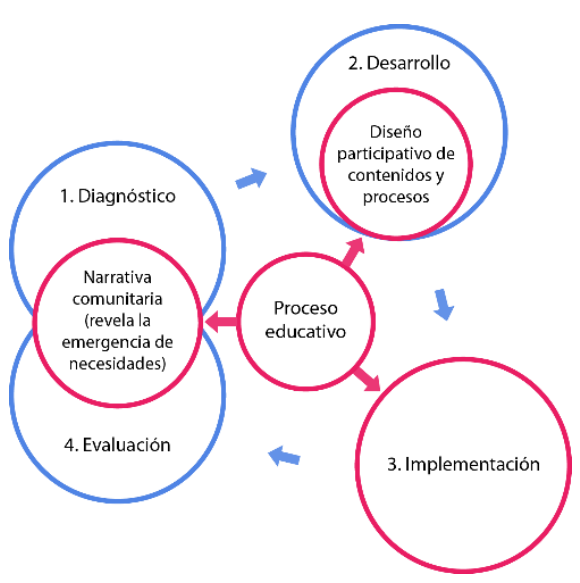

Fuente: elaboración de Teresa Lobo (2021, inédito).

\section{Tabla 1. Etapas de la intervención}

\begin{tabular}{|c|c|c|}
\hline Etapa & Actividades & Productos \\
\hline 1. Diagnóstico & $\begin{array}{l}\text { Trabajo de gabinete. } \\
\text { Consulta a organizaciones } \\
\text { aliadas e informantes locales. } \\
\text { - Procesos de diagnóstico } \\
\text { participativo. } \\
\text { - Entrevistas a participantes. }\end{array}$ & $\begin{array}{l}\text { Diagnóstico de características y } \\
\text { necesidades de la población, que } \\
\text { permita diseñar una intervención } \\
\text { viable, pertinente y culturalmente } \\
\text { sensible. } \\
\text { - Delimitación de la temática } \\
\text { comunitaria: prioridad de problemas } \\
\text { por atender con causas, } \\
\text { consecuencias y posibles } \\
\text { alternativas. }\end{array}$ \\
\hline $\begin{array}{l}\text { 2. Desarrollo } \\
\text { (diseño de } \\
\text { contenidos, } \\
\text { materiales y } \\
\text { actividades) }\end{array}$ & $\begin{array}{l}\text { Trabajo de gabinete. } \\
\text { Trabajo colectivo del equipo de } \\
\text { implementadores. } \\
\text { Procesos participativos en } \\
\text { comunidad. }\end{array}$ & $\begin{array}{l}\text { Contenidos educativos. } \\
\text { - Material didáctico. } \\
\text { - Presentaciones de contenidos. } \\
\text { - Programa de actividades. }\end{array}$ \\
\hline $\begin{array}{l}3 . \\
\text { Implementación }\end{array}$ & $\begin{array}{l}\text { Actividades de vinculación y } \\
\text { participación comunitaria. } \\
\text { - Talleres educativos. } \\
\text { - Proyectos de arte colectivo. } \\
\text { - Actividades de convivencia y } \\
\text { oferta cultural. } \\
\text { - Actividad de cierre. }\end{array}$ & $\begin{array}{l}\text { Proyectos y acuerdos comunitarios. } \\
\text { - Procesos participativos activos. } \\
\text { Obras artísticas colectivas. } \\
\text { - Muestra pública del trabajo } \\
\text { producido en los talleres. }\end{array}$ \\
\hline 4. Evaluación & $\begin{array}{l}\text { Procesos de evaluación } \\
\text { participativa, en los que la } \\
\text { comunidad construye su propia } \\
\text { narrativa sobre la }\end{array}$ & Evaluación y reporte de resultados. \\
\hline
\end{tabular}




\begin{tabular}{|l|l|l|}
\hline & $\begin{array}{l}\text { transformación de su situación } \\
\text { a lo largo del proyecto. } \\
\text { Acopio de información } \\
\text { (entrevistas). }\end{array}$ & \\
Análisis de información. & \\
\hline
\end{tabular}

Fuente: elaboración de Teresa Lobo (2020, inédito).

Con los años, la aplicación de La Ventana Infinita en proyectos cada vez más complejos y de más largo plazo fue exigiendo adaptaciones que enriquecieron el método. Fue corregido y aumentado en 2015 para incluir la experiencia, ya no solo en educación y resiliencia con niños(as), sino en proyectos participativos con comunidades enteras, agregando la participación comunitaria como objetivo y la acción transformadora como último paso del proceso educativo.

Tras haber probado La Ventana Infinita en circunstancias tan diversas y complejas, estamos seguros de que no hay contexto en el que no pueda ser aplicado con éxito. Sin embargo, el método tiene como limitante que exige recursos que no siempre están disponibles para quienes emprenden un proyecto social comunitario. Para alcanzar sus objetivos, es necesario embarcarse en proyectos de largo plazo, centrados en procesos constantes de participación, educación sensible e investigación cualitativa. Estos aspectos no suelen ser considerados prioritarios por quienes manejan fondos públicos o privados destinados a apoyar proyectos sociales comunitarios. Cada vez más, las convocatorias exigen a las organizaciones que lleven a cabo procesos de educación, participación y evaluación, pero sin considerarlos en los tiempos y montos de financiamiento, como si pudieran darse de manera espontánea. Es necesario dedicar tiempo y recursos al desarrollo y fortalecimiento de capacidades, antes de que los procesos comunitarios lleguen a ser autosustentados y autónomos.

\section{La Red Flexible}

Se trata de un modelo de intervención construido a lo largo de diez años de participación en el proyecto Ha Ta Tukari (Agua nuestra vida). Salud y sostenibilidad para el pueblo wixárika, ${ }^{4}$ en el que, desde su inicio en 2010, se aplicó el método de La Ventana Infinita como componente central del eje de educación del proyecto.

\footnotetext{
${ }^{4}$ El proyecto Ha Ta Tukari opera en comunidades indígenas en extrema pobreza del municipio de Mezquitic, Jalisco, México. Es desarrollado por la Red Ha Ta Tukari, conformada por Isla Urbana, Proyecto ConcentrArte, Lu'um, Instituto Internacional de Recursos Renovables (IRRI-México) y La Ventana.
} 
¿Cómo se gestó el proyecto? Cuando la directora de la organización Proyecto ConcentrArte conoció a un marakame (chamán) wixárika, le propuso un proyecto educativo para los niños de su comunidad. Este lo rechazó argumentando: "Lo que nosotros necesitamos es agua". En 2010, Proyecto ConcentrArte invitó a la organización Isla Urbana, dedicada a la captación de agua de lluvia, a realizar una visita de prospección a La Cebolleta - comunidad wixárika- para comprobar la viabilidad de llevar esa tecnología a la sierra. En esa ocasión, en una ceremonia ante el fuego, el marakame nombró al proyecto Ha Ta Tukari (Agua nuestra vida); la comunidad y las dos organizaciones asumieron el compromiso de trabajar juntos para llevar sistemas de captación de agua de lluvia (SCALL) a La Cebolleta.

Ese mismo año se inició la instalación de SCALL comunitarios y la capacitación técnica de los comités responsables de su mantenimiento. A fin de asegurar el impacto a largo plazo de este nuevo acceso al agua, comenzó el trabajo de educación para la adopción de la tecnología y la promoción de hábitos de higiene con niños y madres de familia. Así nacieron las primeras dos líneas de trabajo de $\mathrm{Ha}$ Ta Tukari: 1. Apropiación de ecotecnologías, y 2. Educación para la salud y la sostenibilidad.

Hacia el segundo año del proyecto, comenzó la instalación de SCALL familiares, se incluyeron en el programa educativo temas ambientales y se iniciaron las actividades culturales para la vinculación comunitaria. Una tercera organización, Lu'um, se integró a la red para acompañar a un grupo de artesanas, aprovechando que la disminución del acarreo del agua permitía a las mujeres dedicar más tiempo a su actividad productiva. Esto significó la formación de otra línea de trabajo: 3. Proyectos Productivos. En 2014, Ha Ta Tukari inició actividades en la localidad de La Laguna, donde se replicaron las actividades realizadas en La Cebolleta y la comunidad decidió crear un huerto comunitario, cuya producción se destinó a la alimentación de los niños en el comedor escolar. Con esto, empezó la línea de trabajo 4. Soberanía Alimentaria y Restauración Ambiental, que promueve la producción orgánica de huertos, así como la restauración y protección de manantiales y suelos. Por último, se creó la última línea de trabajo 5. Empoderamiento Comunitario. Esta dotó al proyecto de la flexibilidad necesaria para responder a la emergencia de necesidades comunitarias, ya que dio cabida a procesos participativos y educativos que aprovechan la sinergia de dos o más líneas de trabajo, o que no corresponden a ninguna de estas, pero son propuestos por la comunidad. Entre sus logros están la construcción de un centro comunitario en La Cebolleta, la creación de una biblioteca y su programa de lectura, la organización de una clínica de medicina tradicional participativa y la oferta de actividades educativas y culturales.

En 2014, IRRI-México se sumó a la red, fungiendo como plataforma administrativa y colaborando en el trabajo de monitoreo y evaluación del proyecto. En 2019 se formalizó la participación de La Ventana como OSC, considerando que sus miembros colaboran desde el inicio del proyecto $\mathrm{Ha} \mathrm{Ta}$ Tukari en el trabajo de educación, empoderamiento e 
investigación.

A la red se fueron sumando a lo largo del tiempo colaboradores independientes, organizaciones con actividades puntuales, donadores y voluntarios. Lo fundamental en el proyecto fue la participación de hombres, mujeres, niños y niñas que integran la comunidad wixárika; de sus líderes y autoridades municipales y tradicionales; de las organizaciones locales, así como de los profesores de las escuelas interculturales de la región, y los médicos y enfermeras de las clínicas locales.

El objetivo de la red se definió así: promover el proceso de transformación de comunidades wixaritari en extrema pobreza y marginación, creando de manera integral y sinérgica condiciones para su sostenibilidad social, ambiental, económica y cultural, en respuesta a sus necesidades y tomando como punto de partida el acceso al agua (Lobo, 2019b).

Lo que se buscaba inicialmente era la solución a un problema y a los derivados del mismo con una intervención eficiente y pertinente que respondía a la exigencia pragmática del proyecto, pero ese objetivo adquirió un nuevo sentido cuando se procuró la transformación de la comunidad -de sus integrantes y su hábitat- orientada hacia logros de sostenibilidad que significaran una vida digna.

El proceso de intervención se acompañó de un trabajo de investigación a lo largo del tiempo. El punto de partida fue un diagnóstico inicial en una comunidad que se ha replicado en versión mejorada en dos comunidades. Después se continuó con un proceso de monitoreo y evaluación que al principio se realizó de forma rudimentaria y fue trabajándose con mayor rigor al paso del tiempo, con base en la Teoría del cambio (Rogers, 2014). A mitad del camino, se realizó una investigación cualitativa con el método de teoría fundamentada (Straus y Corbin, 2002), con el fin de determinar las condiciones que hicieron posible la articulación entre la comunidad La Cebolleta, las organizaciones de la sociedad civil e instancias oficiales, para satisfacer necesidades de la comunidad en pro de su desarrollo sostenible (Lobo, 2013). No partimos de un marco teórico inicial, sino que, siguiendo un procedimiento inductivo, los elementos teóricos fueron determinados a partir de las categorías construidas por los hablantes, mediante el análisis de redes semánticas. Se buscó comprender la experiencia como una totalidad y dar voz a los actores inmersos en ella. En 2019 se hizo una descripción completa del proyecto (Lobo, 2019a), con base en 51 entrevistas abiertas, la aplicación de un cuestionario y los resultados de la evaluación a diez años de distancia. La información recogida y analizada, y la narración de los actores fueron retroalimentado el proceso y contribuyeron a hacer ajustes y mejoras al mismo. En varias fases de la indagación y la evaluación fue fundamental la participación de diversos actores, especialmente de integrantes de la comunidad. 
El modelo que surgió de este proceso de investigación se estructura en torno a una red flexible y sinérgica, en la que participan comunidades, OSC, individuos e instituciones que persiguen el empoderamiento y la sostenibilidad comunitaria. Los actores de esta red son convocados a atender las necesidades emergentes de la comunidad, y la articulación entre ellos está basada en la empatía.

Figura 3. Red Flexible. Modelo de intervención para población rural dispersa

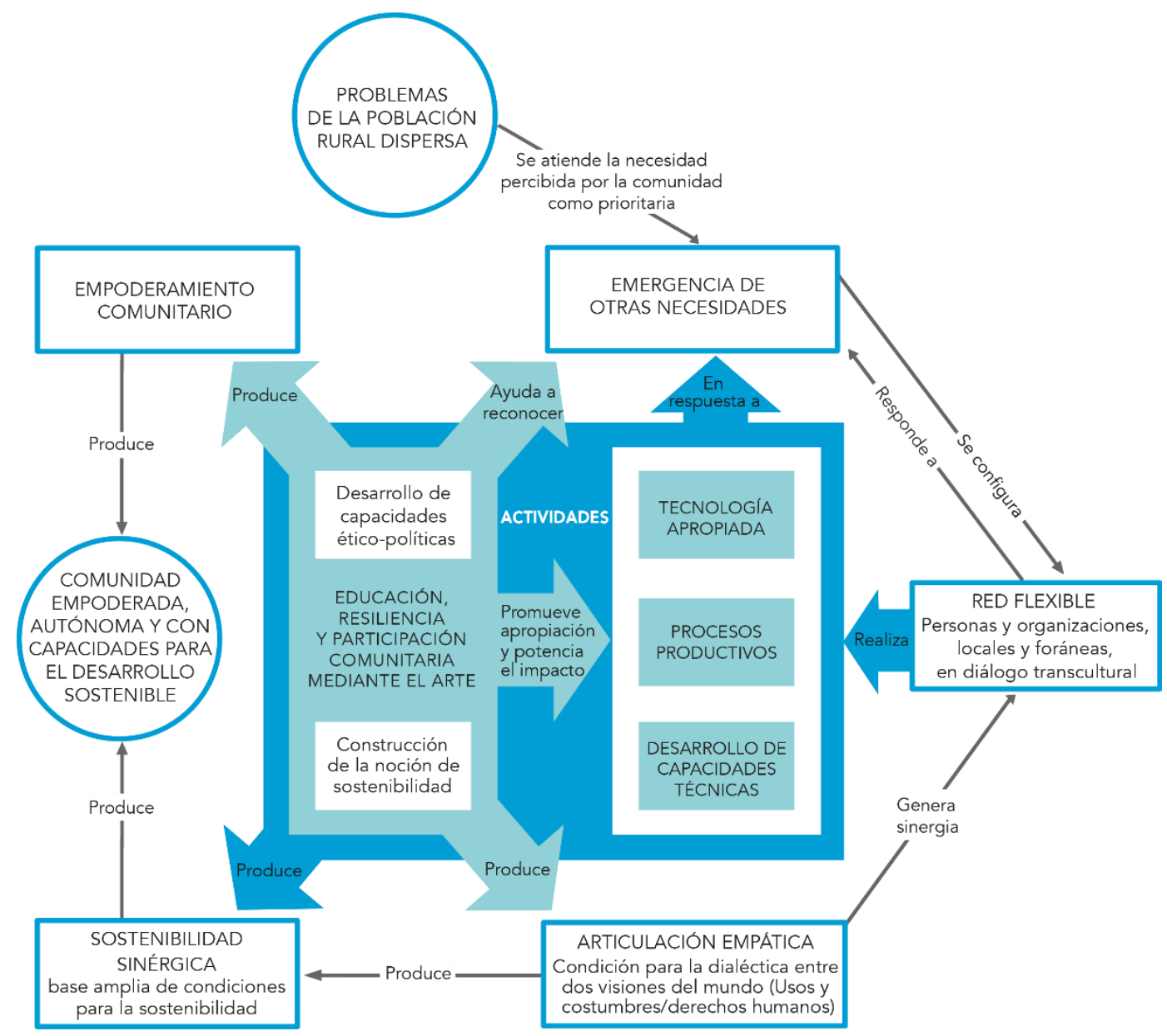

Fuente: elaboración de Teresa Lobo (2020, inédito). 
El término "necesidad" apareció de manera recurrente en las entrevistas hechas a los miembros de la comunidad. El referente teórico que le dio un sentido más amplio fue la Teoría de las necesidades, de Agnes Heller (1996), que afirma que cada grupo humano define sus propias necesidades de acuerdo con su cultura, sus costumbres, su historia y su moral. Distingue entre: a) necesidades necesarias -por ejemplo, aprender la lengua y las costumbres de la propia cultura- que sumadas a las necesidades vitales, han de satisfacerse para asegurar la subsistencia en condiciones dignas; b) necesidades radicales, llamadas así porque están en la raíz de lo humano; son necesidades cualitativas -como la libertad, la conciencia, el reconocimiento, la creatividad, la socialidad, la justicia- y constituyen la riqueza del espíritu humano, y c) necesidades alienadas, cuya satisfacción va en detrimento de las necesidades radicales $\mathrm{y} / \mathrm{o}$ de las necesidades necesarias.

A partir de la Teoría de las necesidades de Heller, desarrollamos categorías analíticas propias: la articulación empática, la emergencia de necesidades, la red flexible y la sostenibilidad sinérgica. La emergencia de necesidades no es algo momentáneo, sino un proceso que hace posible la atención de problemáticas multifactoriales complejas de la población rural dispersa en localidades de difícil acceso, aprovechando al máximo los recursos locales, tanto naturales como sociales. En situación de extrema marginación, no existen condiciones para atender la mayoría de las necesidades más básicas, mientras que las de tipo radical -como la equidad de género o el derecho de los niños al arte y la cultura-, no pueden revelarse a la comunidad sin antes estar asegurada su supervivencia. La emergencia de necesidades comienza con la atención de la necesidad percibida como prioritaria por la comunidad (el agua fue la necesidad prioritaria en el caso de la comunidad wixárika La Cebolleta). Esto crea condiciones para atender más necesidades necesarias (como mejorar prácticas de higiene para reducir enfermedades), revelar necesidades radicales (fortalecer capacidades de las mujeres para la comercialización de artesanía) y combatir necesidades alienadas (la sobrexplotación de cuerpos naturales de agua y el desperdicio de recursos públicos por la instalación de redes de distribución de agua mal planeadas), de manera que se mantenga el enfoque de sostenibilidad del proyecto.

En torno a la emergencia de necesidades se conforma una red flexible de organizaciones y personas que trabajan en el desarrollo de capacidades de la comunidad, abordando cada aspecto de la problemática de manera transversal y aprovechando cada oportunidad de sinergia. El centro y único elemento permanente de la red flexible es la comunidad. El resto de los actores interviene solo mientras la comunidad lo requiera, considerando que el objetivo final de esa intervención es contribuir a su autonomía. Aunque la comunidad siempre será representada por la asamblea comunitaria, liderada por sus autoridades tradicionales y políticas, la red debe incluir a expertos de la comunidad (por ejemplo, 
conocedores de medicina tradicional, profesores, maestros artesanos y de diferentes oficios) y a organizaciones comunitarias (como cooperativas de artesanas y organizaciones responsables de la producción de huertos comunitarios), que puedan superar las agendas de las autoridades locales, cuando estas no son inclusivas, por ejemplo, cuando no dan voz a las mujeres o favorecen a grupos y familias cercanos a los representantes.

Otra categoría generada por el proyecto es la articulación empática. El concepto de "articulación" emergió de categorías de los hablantes para referirse a las interacciones e interrelaciones: "crear puentes", "tejer la relación", "apoyarse entre todos". La calificamos como "empática", porque este adjetivo resume expresiones como: "reconocernos como humanos", "nos sentimos abrazados", "son parte de nosotros", "con calidez humana". Se trata, entonces, de un reconocimiento basado en la confianza (Honneth, 2010) y no solo del reconocimiento que se concreta en el respeto a los derechos del otro (en abstracto). Sin embargo, la empatía no solo surge de esa forma de la confianza que involucra la amistad y el afecto, también emerge de la solidaridad basada en la estima de sí y del otro, en el develamiento de la vulnerabilidad propia y del otro frente a mí; es de esta forma de relación que surge la cooperación y la participación conjunta.

Las tres formas de reconocimiento -jurídica, personal y social- que según Honneth (2010) se corresponden con las actitudes del respeto, la amistad y la solidaridad, se combinaron de manera conveniente en el proyecto, pero es posible que fuera la estima social, base de la solidaridad, la que contribuyó a dar al proyecto una mayor solidez porque favoreció el crecimiento de las y los participantes, en la perspectiva de ser cada vez más autónomos.

La articulación empática permite salvar las profundas diferencias culturales y la barrera del idioma, mientras mantiene la dialéctica entre dos visiones del mundo -usos y costumbres de la comunidad, por un lado, y la perspectiva de derechos humanos de las OSC, por otro lado- que se retroalimentan y reconstruyen juntas.

La sinergia del trabajo de la Red Flexible, articulada empáticamente en torno a la emergencia de necesidades, permite construir una base amplia de condiciones para la sostenibilidad ambiental, económica, social y cultural de comunidades dispersas y en extrema marginación. A esto lo llamamos sostenibilidad sinérgica.

A miembros de la comunidad wixárika (Lobo, 2019b) se les preguntó en entrevistas: "¿Qué ha cambiado en tu comunidad desde que inició el proyecto?". Sus respuestas permiten constatar que las nuevas prácticas desplegadas por ellos fueron aquellas que consideraron deseables y necesarias: "Antes no hablábamos las mujeres. Ahora podemos hablar de lo que sentimos o lo que pensamos entre mujeres. Algunos hombres ya comprenden porque nos han ayudado"; "Con las cisternas, ya se ahorra tiempo. También hay 
beneficio cuando venden artesanías. Se ahorra leña con las estufas, menos acarreo y sin humo en la casa. Los niños aprenden en los talleres, pintan, cantan"; "Antes, si hiciéramos un viaje en el tiempo, la gente no era abierta. Estaba metida en sus cosas. Yo he notado mucho cambio en los niños. Ya son más sociables. Esta cooperativa ha traído ingresos"; "Por el agua, los huertos. A los niños les han ayudado. A los niños les enseñaron de todo, a lavar las manos"; "Antes de la captación del agua había que acarrear. Nos beneficiamos. El centro comunitario es una oportunidad muy importante para la venta de artesanías, porque no hay que salir a la ciudad a vender"; "Ya soy una líder comunitaria."

La teoría de las prácticas sociales (Ariztía, 2017) nos dio una base para constatar que las nuevas prácticas que imbrican el cambio social son aquellas que contribuyen a satisfacer necesidades necesarias y radicales. Las condiciones que hicieron posible el cambio fueron: a) un conjunto de saberes hacer y habilidades que fueron forjando en interacción con distintos miembros de la red flexible; b) conocimientos que fueron construyendo en torno a sus necesidades, problemas y posibles soluciones, articulados a un horizonte de sentido que fueron compartiendo y extendiendo; c) fue esto último lo que facilitó que ellos mismos generaran las condiciones materiales (recursos, infraestructura) para la realización de las nuevas prácticas que revelan la transformación social.

\section{Conclusiones}

El método La Ventana Infinita permite corroborar el supuesto freiriano de que la educación es una praxis cuando se hace efectiva la dialéctica teoría y práctica. Esto implica que el método siempre está en proceso de construcción y que se asume de manera crítica.

El trabajo realizado en diversos contextos ha permitido constatar que el proceso sensible de La Ventana Infinita promueve activamente la empatía, que es el principio de la articulación de la Red Flexible. Además, dicho proceso contribuye a que el participante reconozca sus necesidades y sea capaz de expresarlas. Particularmente, contribuye a revelar necesidades radicales.

El desarrollo de capacidades para la cooperación y la comunicación por parte de todos los actores involucrados es indispensable para la participación comunitaria.

El desarrollo de procesos artísticos en proyectos de participación comunitaria contribuye a generar agencia y empoderamiento de individuos y comunidades.

Un proceso educativo realizado con mirada holística y enriquecido por el análisis permite construir alternativas para atender las necesidades comunitarias de manera sostenible, considerando cuatro dimensiones: social, ambiental, cultural y económica. 


\section{Agradecimientos}

En diversos momentos del proceso de intervención e investigación se contó con el apoyo de: Casa Lamm, Fundación Amigos del Museo del Prado, Fundación Dondé, Fundación Lala, Fundación Merced, Fundación Pepsico, Indesol, Sistema.Bio, W. K. Kellogg Foundation y la Red Ha Ta Tukari: IRRI-México A.C., Isla Urbana, La Ventana, Lu'um A.C. y Proyecto ConcentrArte A.C.

\section{Bibliografía}

Agüero, J. y Riva Palacio, L. (2005). Fluidez, flexibilidad y originalidad. La creatividad y el arte como disparadores de una propuesta pedagógica. México, documento de trabajo de Proyecto ConcentrArte (inédito).

Ariztía, T. (2017). La teoría de las prácticas sociales: particularidades, posibilidades y límites. Cinta moebio, (59), 221-234.

Arnheim, R. (2002). Arte y percepción visual ( $2^{\mathrm{a}}$ ed.) Madrid: Alianza Forma.

Briseño-Roa, J. (2019). La construcción cotidiana de un modelo pedagógico alternativo en educación indígena: entre la participación comunitaria y el uso continuo de la lengua indígena. De Prácticas y Discursos. Cuadernos de Ciencias Sociales, Año 9, (13), 1-23.

Carr, W. (2020). Una teoría para la educación. Hacia una investigación educativa crítica. Madrid: Morata.

Chacón-Ortiz, M. (2015). El proceso de evaluación en educación no formal: Un camino para su construcción. Revista Electrónica Educare, (2)19, 21-35.

De Luca, S.L. (2004). El docente y las inteligencias múltiples. Revista Iberoamericana De Educación, (1)34, 1-12.

Elster, J. (1994). Justicia local. De qué modo las instituciones distribuyen bienes escasos y cargas necesarias (Trad. E. Alterman). Barcelona: Gedisa.

Fernández Poncela, A.M (2011). Antropología de las emociones y teoría de los sentimientos. Revista Versión Nueva Época, 26, 315-339.

Freire, P. (1978a). La educación como práctica de la libertad. México: Siglo XXI (1a ed. de 1969). 
(1978b). Pedagogía del oprimido. México: Siglo XXI (1ª ed. de 1970).

Fuente Carrasco, M.E (2012). La comunalidad como base para la construcción de resiliencia social ante la crisis civilizatoria. Polis, Revista de la Universidad Bolivariana, (11)33, 1-16.

Gardner, H. (1993). Estructuras de la mente: teoría de las inteligencias múltiples (2a ed. en español aumentada). México: FCE.

Golemann, D. (1995). La inteligencia emocional. Editorial Kairos

Grotberg, E. (1995). Proyecto internacional de resiliencia: promoción de la resiliencia en los niños. Birmingham: Centro Internacional de Investigaciones Civitan, Universidad de Alabama (paper).

Guilford, J.P. (1958). ¿Se puede desarrollar la creatividad? Educación artística, 11: 6, 3-18. (1980). La creatividad. En Beaudot, A. (ed.) La Creatividad. Madrid: Narcea (1ª ed. 1950 "Creativity" en American Psichologist, 14).

Jiménez-Naranjo, Y. y Sánchez-Antonio, J.C. (2020). Pluralismo epistémico, alteridad, comunidad y escuela: una relación que discurtir. De Prácticas y Discursos. Cuadernos de Ciencias Sociales, Año 9, (13), 1-24.

Kandinsky, V. (1989). Sobre la cuestión de la forma. En Vasily Kandinsky y Franz Marc (eds.) El Jinete Azul. Paidós Estética (versión original de 1912).

Kotliarenco, M.A.; Cáceres, I. y Fontecilla, M. (1997). Estado de arte en resiliencia. Organización Panamericana de la Salud, Oficina Sanitaria Panamericana, oficina regional de la Organización Mundial de la Salud.

Heller, A. (1996). Una revisión de la teoría de las necesidades (Trans. Á. Rivero). Barcelona, España: Paidós-ICE/UA.

Lobo, T. (2011). Arte, educación para la paz y resiliencia ante la violencia. En el marco del Foro Arte y Ciencias Penales. México: Instituto Nacional de Ciencias Penales (paper). (2013). Ha Ta Tukari. Articulación entre organizaciones y comunidad para el desarrollo sostenible en la sierra huichol. México: ConcentrArte, Indesol. (2019a). Ha Ta Tukari, Agua Nuestra Vida. México: Fundación Pepsico, Concentrarte, Isla Urbana, IRRI, Lu'um, La Ventana.

(2019b). Ha Ta Tukari. Agua, salud y sostenibilidad para el pueblo wixárica. Reporte de resultados 2014-2019. México: Fundación Pepsico, Concentrarte, Isla Urbana, IRRI, Lu'um, La Ventana. 
(2020). La Ventana Infinita. Método de trabajo mediante el arte para la atención de niños y comunidades en desventaja social. México: La Ventana (Documento de trabajo inédito producido en 2010, corregido y aumentado en 2015 y 2020).

Lobo, T.; Cervantes, A. y Frank, D. (2016). Ha Ta Tukari. Reporte de evaluación de las líneas de trabajo Educación para la salud y la sostenibilidad y Fortalecimiento y empoderamiento comunitario. México: Fundación Pepsico, ConcentrArte.

Lobo, T. y Enríquez, P. (2018). El dragón del nuevo fuego. Biodigestor y sostenibilidad. México: IRRI, ConcentrArte, Kellogg Foundation.

Martínez Fernández, M. (2003) ¡Cambiamos por favor! Diario del taller de dibujo de Gilberto Aceves Navarro ( $2^{\mathrm{a}}$ ed.) México: Colección Arte e Imagen, Conaculta.

Mazzarini, M.N.; Narváez, D. y Suanno, J. (2016, 6 y 7 de octubre). Construyendo lazos sociales a partir de la educación no formal para la consolidación de la identidad y el empoderamiento en contextos vulnerables. En el marco de las VIII Jornadas de Investigación en Disciplinas Artísticas y Proyectuales. Universidad Nacional de La Plata (paper).

Nussbaum, M. (1999). Women and Equality: The Capabilities Approach. International Labour Review (3)138, 227-245. (2008). Paisajes del pensamiento: La inteligencia de las emociones. Barcelona: Paidós.

Pick, S.; Sirkin, J.; Ortega, I.; Osorio, P.; Martínez, R.; Xocolotzin, U. y Givaudan, M. (2007). Escala Para Medir Agencia Personal y Empoderamiento (ESAGE). Revista Interamericana de Psicología, (3)41, 295-304.

Rogers, P. (2014). La teoría del cambio, Síntesis metodológicas: evaluación de impacto $N^{\circ} 2$. Florencia: Centro de Investigaciones de Unicef.

Selles, J.F. (2006). La distinción en los sentidos internos. En Curso y apuntes sobre la antropología filosófica. Facultad de Filosofía y Letras, Universidad de Navarra (inédito).

Sen, A. (2010). La Idea de La Justicia. Madrid: Taurus Ediciones.

Soler Maso, P.; Trilla Bernet, J.; Jiménez-Morales, M. y Úcar Martínez, X. (2017). La construcción de un modelo pedagógico del empoderamiento juvenil: espacios, momentos y procesos. Pedagogía social. Revista interuniversitaria, 30, 19-34.

Sperry, R.W. (1968). Desconexión del hemisferio y unidad en la conciencia. Psicólogo estadounidense, (10)23, 723-733. 
Strauss, A. y Corbin, J. ([1998] 2002). Bases de la investigación cualitativa. Técnicas y procedimientos para desarrollar la teoría fundamentada (Trad. E. Zimmerman). Antioquía, Colombia: Universidad de Antioquía.

Úcar, X. (2018). La pedagogía social frente a las desigualdades y vulnerabilidades en la sociedad. Zona Próxima, 29, 52-69. 